\title{
Measurement of activity of urea resistant neutrophil alkaline phosphatase as an antenatal screening test for Down's syndrome
}

\author{
Howard S Cuckle, Nicholas J Wald, Sandra F Goodburn, Joan Sneddon, John A L Amess, \\ Susan Carlson Dunn
}

\begin{abstract}
Objective-To investigate the value of measuring maternal urea resistant neutrophil alkaline phosphatase activity as an antenatal screening test for Down's syndrome.

Design-Case-control study of blood samples collected at nine to 27 weeks of pregnancy.

Setting - Antenatal clinics in London and Oxford.

Patients - 72 Women whose fetuses had been diagnosed by amniocentesis or chorionic villus sampling as having Down's syndrome and 156 women whose fetuses did not have the syndrome. Only singleton pregnancies were studied.

Main outcome measure-Activity of urea resistant neutrophil alkaline phosphatase measured cytochemically.

Results - The median enzyme activity in the index patients was 1.65 times the expected median for the controls at the same duration of pregnancy $(\mathbf{p}<0.0001 ; 95 \%$ confidence interval 1.56 to $1 \cdot 74)$. A cut off value that identified the $5 \%$ of control patients with the highest activities yielded a rate of detection of Down's syndrome of $79 \%$ ( $95 \%$ confidence interval 70 to $89 \%$ ).

Conclusion-Activity of urea resistant neutrophil alkaline phosphatase is an effective maternal blood marker for Down's syndrome. Its use in antenatal screening could lead to a substantial improvement in the detection of this disorder. Before introducing the test into routine medical practice it will have to be automated so that it can be used on a large scale and is less subjective.
\end{abstract}

\section{Introduction}

Several substances are present at abnormally high or

Department of

Environmental and

Preventive Medicine,

Medical College of

St Bartholomew's Hospital,

London EC1M 6BQ

Howard S Cuckle, DPHIL, reader

Nicholas J Wald, FRCP, head of department

Sandra F Goodburn, PHD, research assistant

Joan Sneddon, RN, research assistant

\section{Department of}

Haematology, St

Bartholomew's Hospital,

London EC1A 7BE

John A L Amess, FRCP, consultant

Susan Carlson Dunn, FIMLS, chief medical laboratory scientific officer

Correspondence to:

Dr Cuckle.

BrMed f 1990;301:1024-6 notified whenever Down's syndrome was diagnosed antenatally in any of the eight cytogenetics laboratories in the four Thames regional health authorities. The study was restricted to singleton pregnancies. With the agreement of the consultants concerned we contacted the women in whom the diagnosis had been made (the index patients) and invited them to provide a blood sample. All 72 who were invited agreed; Down's syndrome had been diagnosed after amniocentesis in 70 and after chorionic villus sampling in two. The blood sample was collected at a median of 19 weeks of pregnancy, before a therapeutic abortion; a blood film was made immediately.

Forty six women with singleton pregnancies in which the fetus did not have Down's syndrome (controls) were identified in the same way as the index patients (after amniocentesis in $\mathbf{4 5}$ and after chorionic villus sampling in one) after confirmation that the fetus had a normal karyotype. The blood samples were collected at a median of 21 weeks of pregnancy. This was later than in the index patients because the interval between amniocentesis (or chorionic villus sampling) and the collection of blood for measurement of the enzyme activity was longer in the controls: the cytogenetics laboratories usually reported aneuploidy straight away but reported a normal karyotype only after less severe chromosomal changes had been excluded. To obtain more controls at an earlier stage of pregnancy so that enzyme activities in the index patients could be compared with those in controls whose pregnancy was of the same duration we identified 110 women with singleton pregnancies attending their first routine antenatal clinic at the John Radcliffe Maternity Hospital, Oxford, who provided blood samples.

Blood films from the 72 index patients and 156 controls were stained for urea resistant neutrophil alkaline phosphatase in the department of haematology at St Bartholomew's Hospital. A semiquantitative technique was used to measure the activity of the enzyme. ${ }^{7}$ Blood films were fixed in a solution of methanol formaldehyde for one minute, washed, dried, and then stored at $-20^{\circ} \mathrm{C}$ until required. Before being stained the films were treated with $1.5 \mathrm{M}$ urea in $0.1 \mathrm{M}$ Trisma buffer (Sigma), pH 9.8, at $37^{\circ} \mathrm{C}$ for 15 minutes They were then incubated with $\beta$ naphthol AS-BI phosphate (Sigma) as a substrate plus fast red violet $\mathrm{LB}$ (Sigma) as a coupling diazodye at $\mathrm{pH} 10.0$ at $37^{\circ} \mathrm{C}$ for 15 minutes, washed briefly in tap water, and counterstained with aqueous haematoxylin for five minutes. One hundred neutrophils on each slide were individually scored according to the intensity of the staining of the cytoplasmic granules $(0=$ no granules, stain absent or faint; $1=$ few scattered granules, stain pale pink; $2=$ many regularly dispersed granules, stain moderately pink; $3=$ numerous granules throughout the whole of the cytoplasm, stain dark pink to red). The scores were summed for each slide. The scoring was done by one of two people, who did not know whether the slide was from an index patient or a control. There was a systematic absolute difference between the scorers' total scores per slide, and to allow

\section{Patients and methods}

During 1987-9 the department of environmental and preventive medicine at St Bartholomew's Hospital was 
for this in the analysis the average difference in score between them (55) was added to the lower scorer's results. As the scores increase with advancing pregnancy in early pregnancy they were expressed as multiples of the expected (normal) median for the control patients whose pregnancy was of the same duration. The expected medians were obtained by linear regression of the observed control median values for each week of pregnancy on the median duration of pregnancy in days, weighted by the number of women at each week. Duration of pregnancy was measured from the first day of the last menstrual period.

TABLE I - Number (percentage) of patients whose fetuses had Down's syndrome and controls with urea resistant neutrophil alkaline phosphatase activity greater than or equal to various multiples of the normal median at same duration of pregnancy

\begin{tabular}{lcc}
\hline $\begin{array}{l}\text { Multiples } \\
\text { of the } \\
\text { median }\end{array}$ & $\begin{array}{c}\text { Index } \\
\text { patients } \\
(\mathbf{n}=72)\end{array}$ & $\begin{array}{c}\text { Controls } \\
(\mathbf{n}=156)\end{array}$ \\
\hline$\geqslant 1.65$ & $36(50)$ & $2(1)$ \\
$\geqslant 1.60$ & $41(57)$ & $2(1)$ \\
$\geqslant 1.55$ & $48(67)$ & $2(1)$ \\
$\geqslant 1.50$ & $49(68)$ & $2(1)$ \\
$\geqslant 1.45$ & $53(74)$ & $6(4)$ \\
$\geqslant 1.40$ & $57(79)$ & $8(5)$ \\
$\geqslant 1.35$ & $60(83)$ & $13(8)$ \\
$\geqslant 1.30$ & $64(89)$ & $18(12)$ \\
$\geqslant 1.25$ & $64(89)$ & $30(19)$ \\
$\geqslant 1.20$ & $66(92)$ & $42(27)$ \\
\end{tabular}

TABLE II-Median (25th and 75th centiles) urea resistant neutrophil alkaline phosphatase activity (expressed as multiples of the normal median at same duration of pregnancy) in patients whose fetuses had Down's syndrome and controls according to maternal age, time between diagnostic procedure (amniocentesis or chorionic villus sampling) and enzyme test, and reason for diagnostic procedure

\begin{tabular}{|c|c|c|c|c|c|c|}
\hline & \multicolumn{3}{|c|}{ Index patients } & \multicolumn{3}{|c|}{ Controls } \\
\hline & No & Median & $\begin{array}{l}\text { (25th, } 75 \text { th } \\
\text { centiles) }\end{array}$ & No & Median & $\begin{array}{l}\text { (25th, } 75 \text { th } \\
\text { centiles }\end{array}$ \\
\hline \multicolumn{7}{|l|}{ Maternal age (years): } \\
\hline$\leqslant 37$ & 15 & $1 \cdot 68$ & $(1 \cdot 41,2 \cdot 10)$ & 138 & $1 \cdot 00$ & $(0 \cdot 76,1 \cdot 21)$ \\
\hline $38-39$ & 16 & 1.51 & $(1 \cdot 15,1.79)$ & 11 & $1 \cdot 06$ & $(0.65,1.34)$ \\
\hline$\geqslant 40$ & 41 & 1.73 & $(1.50,1.95)$ & 7 & 1.08 & $(1.03,1.27)$ \\
\hline \multicolumn{7}{|c|}{$\begin{array}{l}\text { Interval between diagnostic procedure } \\
\text { and enzyme test (days): }\end{array}$} \\
\hline$\leqslant 23$ & 58 & 1.67 & $(1 \cdot 48,1 \cdot 92)$ & 5 & 0.95 & $(0 \cdot 84,1 \cdot 40)$ \\
\hline $24-25$ & 4 & $1 \cdot 36$ & $(0.91,1.99)$ & 6 & 0.99 & $(0 \cdot 72,1 \cdot 26)$ \\
\hline $26-27$ & 6 & $1 \cdot 88$ & $(1 \cdot 46,2 \cdot 18)$ & 6 & 0.93 & $(0.53,1.24)$ \\
\hline$\geqslant 28$ & 4 & 1.49 & $(1.41,1.75)$ & 29 & 1.06 & $(0 \cdot 66,1 \cdot 25)$ \\
\hline No diagnostic procedure & & & & 110 & $1 \cdot 00$ & $(0 \cdot 76,1 \cdot 21)$ \\
\hline \multicolumn{7}{|c|}{ Indication for diagnostic procedure: } \\
\hline Advanced maternal age & 64 & 1.67 & $(1 \cdot 47,2 \cdot 00)$ & 18 & $1 \cdot 13$ & $(0.83,1 \cdot 27)$ \\
\hline Low $\alpha$ fetoprotein & 5 & $1 \cdot 38$ & $(1 \cdot 17,1 \cdot 75)$ & 26 & $1 \cdot 00$ & $(0.58,1 \cdot 08)$ \\
\hline Other & 3 & 1.73 & $(1 \cdot 44,1 \cdot 76)$ & 2 & 1.07 & \\
\hline No diagnostic procedure & & & & 110 & $1 \cdot 00$ & $(0 \cdot 76,1 \cdot 21)$ \\
\hline Total & 72 & $1 \cdot 65$ & $(1 \cdot 42,1.93)$ & 156 & $1 \cdot 02$ & $(0 \cdot 76,1 \cdot 21)$ \\
\hline
\end{tabular}

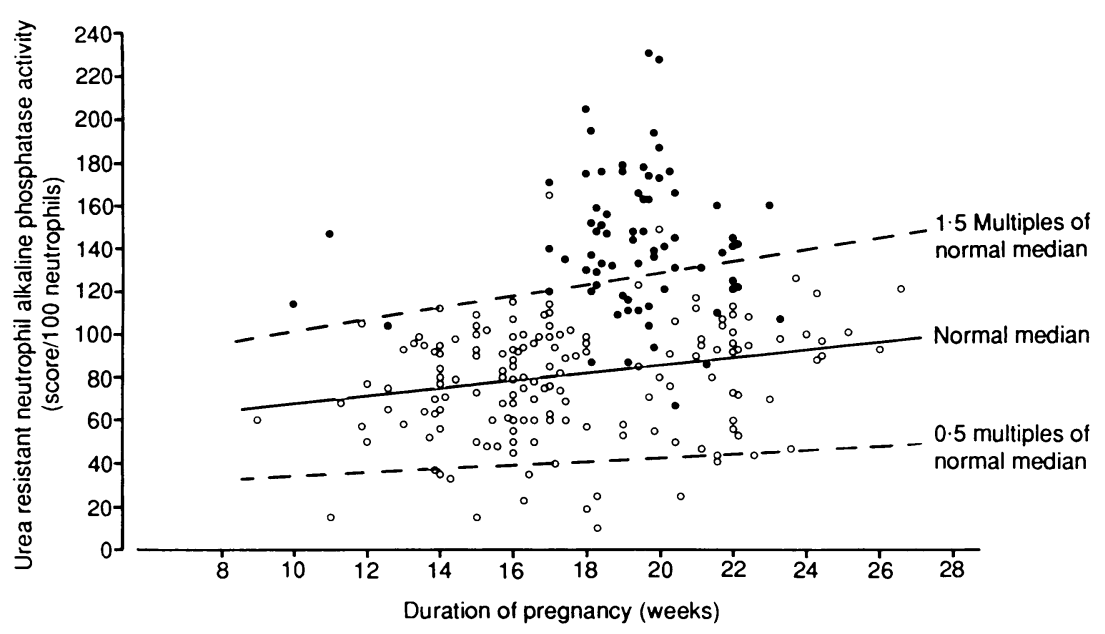

Urea resistant neutrophil alkaline phosphatase activity according to duration of pregnancy in 72 women whose fetuses had Down's syndrome $(\bullet)$ and 156 controls $(O)$ syndrome was $79 \%$ ( $95 \%$ confidence interval 70 to $89 \%)$.

Table II shows the median and 25th and 75 th centiles of urea resistant neutrophil alkaline phosphatase activity in the index and control patients according to maternal age, the indication for amniocentesis (or chorionic villus sampling), and the time between that procedure and measurement of the enzyme activity. There was no obvious association between the enzyme activity and any of these three variables.

\section{Discussion}

We confirmed the observations of Grozdea et al that blood urea resistant neutrophil alkaline phosphatase activity is raised in pregnant women whose fetus has Down's syndrome $e^{5}$ we found that the median activity was 1.65 times that in women whose fetuses did not have the syndrome. When a cut off value of 1.40 multiples of the normal median was used $79 \%$ of the index patients were identified with a rate of false positive results of $5 \%$. At present the single most effective marker for Down's syndrome is human chorionic gonadotrophin concentration, which detects $37 \%$ of women whose fetuses have the syndrome at a cut off that yields a 5\% false positive rate (derived from gaussian distributions with the parameters reported previously ${ }^{1}$ ). Measurement of urea resistant neutrophil alkaline phosphatase activity is therefore a more discriminating test. To our knowledge no other single blood test can identify Down's syndrome so effectively.

We do not know why the activity of urea resistant neutrophil alkaline phosphatase is raised in pregnant women whose fetuses have Down's syndrome, although it may be related to the observation that this activity is raised in people with Down's syndrome. ${ }^{8}$ The enzyme activity is also raised in women who in the past have had a pregnancy in which the fetus had Down's syndrome ${ }^{6}$ an observation that cannot be readily explained by a direct fetal effect unless the fetus provides a signal to the mothers' neutrophils or a neutrophil precursor that persists after the pregnancy.

Our results were not influenced to any great extent by the fact that most samples were collected after amniocentesis or chorionic villus sampling as in the controls the medians were similar in the women who did (1.05 multiples of the normal median) and did not ( 1.00 multiples of the normal median) have either procedure (table II). Moreover, there was no correlation between the enzyme activity and the time since amniocentesis or chorionic villus sampling.

At present screening for Down's syndrome is best done by measuring $\alpha$ fetoprotein, unconjugated oestriol, and human chorionic gonadotrophin concentrations; these together with maternal age can identify $61 \%$ of pregnancies in which the fetus has Down's syndrome with a false positive rate of $5 \% .^{1}$ Adding measurement of urea resistant neutrophil alkaline phosphate activity will increase the detection rate for the same false positive rate, but the test is not yet ready for routine use. More information is needed on the performance of the test earlier in pregnancy, at about 16 weeks, when the other screening tests for Down's syndrome and neural tube defects are carried out. The shape of the frequency distributions of the enzyme activity in women whose fetuses do and do not have the syndrome needs to be more precisely specified and the correlation, if any, with the other markers estimated. Also, the test needs to be automated to make it less labour intensive and less subjective. When this has been accomplished it should be a useful practical advance in antenatal screening for Down's syndrome.

We thank Professor M Bobrow, Dr C Berry, Miss C Brooker, Mr L Butler, Mr G Davies, Dr D E Heaton, Miss L 
Hill, Dr M Lucas, Dr M Ridler, and Dr J Taylor for identifying the index patients and controls and Mrs Nora Jones for arranging for the collection of samples in Oxford. We are especially grateful to the patients who agreed to be included in the study and the late Professor Sir Alec Turnbull and other obstetricians who approached patients on our behalf and agreed to our interviewing them. The study was supported by Action Research for the Crippled Child.

1 Wald NJ, Cuckle HS, Densem JW, et al. Maternal serum screening for Down's syndrome in early pregnancy. Br Med f 1988;297:883-7.

2 Bartels I, Lindemann A. Maternal levels of pregnancy-specific beta ${ }_{1}$-glycoprotein (SP-1) are elevated in pregnancies affected by Down's syndrome. Hum Genet 1989;80:46-8.
Wald NJ, Cuckle HS, Densem J. Maternal serum specific beta ${ }_{1}$-glycoprotein in pregnancies associated with Down's syndrome. Lancet 1989;ii:450.

Cuckle HS, Wald NJ, Densem JW, et al. The effect of smoking in pregnancy on maternal serum alpha-fetoprotein, unconjugated oestriol, human chorionic gonadotrophin, progesterone and dehyroepiandrosterone sulphate levels. Brf Obstet Gynaecol 1990;97:272-6.

Grozdea J, Vergnes H, Martin J. Urea-resistant neutrophil alkaline phosphatase in mothers with trisomy 21 pregnancy. Lancet 1983;ii:799.

6 Grozdea J, Maret A, Vergnes H, et al. Cytochemical and biochemical studies on neutrophil alkaline phosphatase in parents of trisomy 21 children. Hum Gene 1984;67:313-6.

7 Kaplow LS. Cytochemistry of leucocyte alkaline phosphatase. Am f Clin Pathol 1963;39:439-49.

8 Krone A, Wolf U. The biochemical genetics of man. London: Academic Press, 1972.

(Accepted 1 August 1990)

\title{
Accuracy of clinical diagnosis of Alzheimer's disease
}

\author{
Alistair Burns, Philip Luthert, Raymond \\ Levy, Robin Jacoby, Peter Lantos
}

\section{Institute of Psychiatry,}

London SE5 8AF

Alistair Burns, MRCPSYCH,

honorary lecturer, section of old age psychiatry

Philip Luthert, MRCPATH, senior lecturer, department of

Raymond Levy, FRCPSYCH, professor of old age psychiatry

Robin Jacoby, FRCPSYCH, consultant psychiatrist, section of old age psychiatry Peter Lantos, FRCPATH, professor of neuropathology

Correspondence to: $\mathrm{Dr}$ Burns.

BrMed f 1990;301:1026 neuropathology

There is no specific antemortem marker for Alzheimer's disease, and the diagnosis may be uncertain even after examination of cerebral tissue. ${ }^{1}$ In 1988 Homer et al emphasised the problems of correctly predicting the pathological findings in various types of dementia and implied that Alzheimer's disease was often not confirmed at necropsy. ${ }^{2}$ The aim of our study was to assess prospectively the ability of current rigorous clinical criteria to diagnose Alzheimer's disease successfully during life.

\section{Patients, methods, and results}

We studied elderly psychiatric patients living in the area covered by Camberwell Health Authority, London. Altogether 180 were enrolled in the study, of whom 86 had died by three years. Necropsy was performed on 54 patients, and we report here on the first 50 .

The clinical criteria used were those of the National Institute of Neurological and Communicative Disorders and Stroke and the Alzheimer's Disease and Related Disorders Association. ${ }^{3}$ Probable Alzheimer's disease was diagnosed in patients with a history of a slowly progressive dementia without concomitant physical illness. Possible Alzheimer's disease was diagnosed in patients with atypical features of the disease or physical illness. Definite Alzheimer's disease was diagnosed only when the disease was confirmed by histopathological examination - that is, by the finding of widespread neocortical and hippocampal disease with plaques or neurofibrillary tangles, or both. Diffuse Lewy body disease was diagnosed when Lewy bodies were found not only in the substantia nigra and

Relation between diagnosis of Alzheimer's disease (probable or possible) based on clinical criteria and neuropathological diagnosis, and ability of clinical criteria to predict neuropathological findings of Alzheimer's disease and exclude vascular disease

\begin{tabular}{|c|c|c|c|}
\hline & \multicolumn{2}{|c|}{$\begin{array}{l}\text { Diagnosis of Alzheimer's disease from } \\
\text { clinical criteria }\end{array}$} & \multirow[b]{2}{*}{ Total $(n=50)$} \\
\hline & Probable $(\mathrm{n}=32)$ & Possible $(n=18)$ & \\
\hline \multicolumn{4}{|l|}{ Neuropathological diagnosis: } \\
\hline Alzheimer's disease alone & 24 & 10 & 34 \\
\hline Alzheimer's disease and vascular disease & 2 & 3 & 5 \\
\hline Alzheimer's disease and cortical Lewy & & & \\
\hline body disease & 2 & 1 & 3 \\
\hline Vascular disease alone & & 2 & 2 \\
\hline Cortical Lewy body disease alone & 3 & & 3 \\
\hline No diagnosis & 1 & 2 & 3 \\
\hline \multicolumn{4}{|c|}{$\begin{array}{l}\text { Ability of clinical criteria to predict pathological } \\
\text { findings of Alzheimer's disease: }\end{array}$} \\
\hline Findings present & 28 & 14 & 42 \\
\hline Findings absent & 4 & 4 & 8 \\
\hline \multicolumn{4}{|c|}{ Ability of clinical criteria to exclude vascular disease: } \\
\hline Vascular disease absent & 30 & 13 & 43 \\
\hline Vascular disease present & 2 & 5 & 7 \\
\hline
\end{tabular}

locus coeruleus but also in the cortex, particularly in the parahippocampal gyrus. Vascular damage was considered to be important when multiple, widespread macroscopic or microscopic lesions were identified.

The average age of the 50 patients studied was $82 \cdot 3$ years (range 70-99). The table shows the numbers of patients predicted by the clinical criteria to have probable and possible Alzheimer's disease and the neuropathological diagnoses. The criteria for predicting probable Alzheimer's disease had a sensitivity of $88 \%(28 / 32)$, and those for predicting possible Alzheimer's disease had a sensitivity of $78 \%$ (14/18). We could not assess specificity as we did not include in the study patients who did not satisfy the clinical criteria for the disease. The table also shows the ability of the criteria to exclude patients with vascular disease. Two patients had evidence of only vascular disease; in both cases the criteria had predicted possible Alzheimer's disease.

\section{Comment}

The main finding of this study was that Alzheimer's disease can be diagnosed accurately during life by strictly applying the criteria of the National Institute of Neurological and Communicative Disorders and Stroke and the Alzheimer's Disease and Related Disorders Association without the need for extensive investigation and resources. The rate of agreement between clinical and histological diagnoses of the disease varies from $50 \%{ }^{2}$ to over $95 \%,{ }^{4}$ but studies in which agreement has been $90 \%$ or above have all used the criteria that we used here. This is the first study to attempt to validate the criteria for possible Alzheimer's disease; it shows that the disease may be diagnosed in patients with other physical illness (such as diabetes and hypertension).

Cortical Lewy body disease was found in six patients (12\%), a prevalence similar to that found by Perry $e t$ $a l,{ }^{5}$ which suggests that this disease is the second commonest neurodegenerative dementia in old age.

The ability of the clinical criteria that we used to diagnose Alzheimer's disease in $88 \%$ of patients confirms their validity. Such successful clinical prediction of disease is unusual in any branch of medicine.

This work was supported by grants from the Medical Research Council to RL, RJ, and the institute's brain bank in the department of neuropathology.

\footnotetext{
Wisniewski H, Rabe A, Zigman W, Silverman W. Neuropathological diagnosis of Alzheimer's disease. I Neuropathol Exp Neurol 1989;48:606-9.

Homer A, Honavar M, Lantos P, Hastie I, Kellett J, Millard P. Diagnosing dementia: do we get it right? $\mathrm{Br}$ Med $\mathcal{f}$ 1988;297:894-6.

3 McKhann G, Drachman D, Folstein M, Katzman R, Price D, Stadlan E. Clinical diagnosis of Alzheimer's disease: report of the NINCDS/ADRDA workgroup under the auspices of Department of Health and Human Services task force on Alzheimer's disease. Neurology 1984;34:939-44.

4 Martin E, Wilson R, Penn R, Fox J, Clasen R, Savoy S. Cortical biopsy results in Alzheimer's disease: correlation with cognitive deficits. Neurology 1987:37: $1201-4$

5 Perry R, Irving D, Blessed G, Perry E, Fairbairn A. Clinically and neuropathologically distinct form of dementia in the elderly. Lancet 1989;i:166.
}

(Accepted 13 fulv 1990 ) 